\title{
Erratum to: The content and availability of information affects the evolution of social-information gathering strategies
}

\author{
Eleanor Redstart Brush ${ }^{1}$ • Naomi Ehrich Leonard ${ }^{2} \cdot$ Simon A. Levin $^{3}$
}

Published online: 10 February 2017

(C) Springer Science+Business Media Dordrecht 2017

Erratum to: Theor Ecol (2016) 9:455-476

DOI 10.1007/s12080-016-0301-4

The original version of this article unfortunately contained a mistake. Figure 8 was incorrect. The correct Figure 8 is given below:

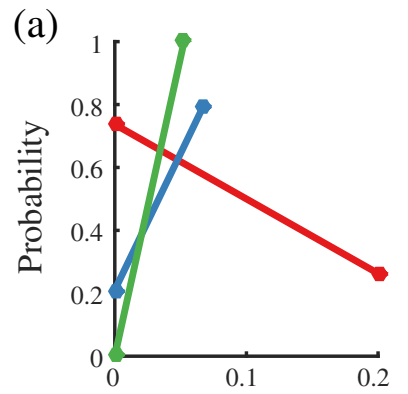

Proportion of neighbors

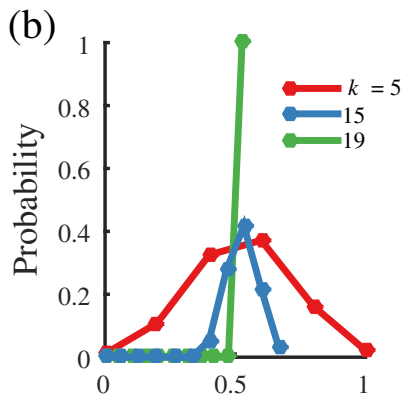

Proportion of neighbors

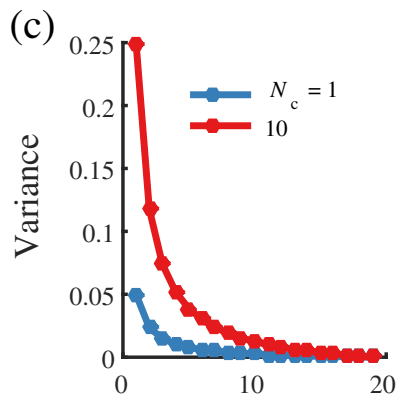

Number of neighbors

The online version of the original article can be found at http://dx.doi.org/ 10.1007/s12080-016-0301-4.

Eleanor Redstart Brush eleanor.brush@gmail.com

1 Program in Quantitative and Computational Biology, Princeton University, Princeton, NJ, USA

2 Department of Mechanical and Aerospace Engineering, Princeton University, Princeton, NJ, USA

3 Department of Ecology and Evolutionary Biology, Princeton University, Princeton, NJ, USA 